\title{
Subclinical Vitamin A Deficiency and Malnourishment among East Timor Refugee Children
}

\author{
Marcelino Correia ${ }^{1}$, V.Swetha E. Jeganathan ${ }^{2 *}$, Nitin Verma ${ }^{3,4}$ \\ ${ }^{1}$ Hospital Nacional Guido Valdares, Toko Baru, Dili, Timor Leste \\ ${ }^{2}$ Kellogg Eye Center, University of Michigan, Ann Arbor, USA \\ ${ }^{3}$ Royal Hobart Hospital, Hobart, Australia \\ ${ }^{4}$ Hobart Eye Surgeons, Hobart, Australia
}

Received: 21 October, 2016; Accepted: 09 November, 2016; Published: 19 November, 2016

*Corresponding author: Jeganathan VS, Kellogg Eye Center, 1000 Wall Street, Ann Arbor, MI 48105, USA, Phone: +1 (734) 763- 8122; Fax +1 (734) 936-2340; E-mail: jvswetha@med.umich.edu

\begin{abstract}
Context/Background: To determine the prevalence and risk factors of vitamin A deficiency (VAD) in children living at refugee camps in East Timor.

Methods: A cross-sectional, community-based study was conducted among 89 children (6 to 72 months old) at two refugee camps in Dili, East Timor. We evaluated socio-economic, demographic, nutrition intake of vitamin $\mathrm{A}$, and examined clinically for xerophthalmia. The World Health Organization (WHO) criterion was used to classify the populations' VAD risk and status.

Results: Of 89 children, $80.9 \%$ received vitamin A supplementation and full immunization, but 5.6\% suffered from night blindness, without xerophthalmia. As recommended by WHO, all children consumed fruits/vegetables containing vitamin A sources more than three times per week. $69.7 \%$ had been regularly breast fed. Yet almost $30 \%$ of the children suffered from moderate to severe malnutrition.

Conclusions: Despite social unrest, no evidence of clinical VAD was found among the refugee children in East Timor. However, subclinical VAD occurred at a level of mild-moderate public health importance, with concurrent malnourishment; consequently, this situation warrants further attention.
\end{abstract}

Keywords: Vitamin A Deficiency; Children; Refugee; Night blindness; Malnutrition

\section{Introduction}

Vitamin A deficiency (VAD) is a key cause of preventable childhood blindness in underdeveloped countries [1-4], particularly among children ages 6 to 72 months $[5,6]$. Approximately 140 million pre-school children suffer from VAD annually, with 4.4 million being affected by xerophthalmia [7-9]. Up to $50 \%$ die within a year of losing their sight $[8,10]$. Improving vitamin A levels of deficient children can increase their survival by $23 \%[8,11]$. The World Health Organization (WHO) and recommendations from other published VAD studies have suggested integrating the administration of immunizations with vitamin A supplementation to reduce the risk of morbidity and mortality $[3,12,13]$.

Countries with social underdevelopment have limited access to healthcare, social services, and education; moreover, they tend to follow traditional beliefs $[3,13,14]$. Populations who are physically isolated from health and social services are often more prone to VAD, partly because of their low socioeconomic status, but also because of the frequent or severe infections resulting from low immunization rates and inadequate treatment [1517]. Concomitant acute respiratory infections and diarrhoeal morbidity may contribute towards morbidity and mortality from VAD [2, 18-20]. Refugees are believed to be at special risk of developing subclinical VAD as well as acute and chronic malnutrition [21]. Inadequate living conditions among refugees, particularly those living in poverty following armed conflict and social displacement has been associated with high mortality in children and infants from VAD [21-24].

The aim of the current study is to examine the risk factors for VAD in children 6 to 72 months old at the refugee camps in Dili, East Timor. To date, the effect of war, civil unrest, and hostile environments in East Timor and their impact on VAD among the refugee population remain poorly understood.

\section{Methods}

A cross-sectional, community-based population study was performed from January 2007 to April 2007 at two refugee camps (Hospital Nacional Guido Valadares and Manleuana) in East Timor. The refugees came from 14 village clusters near Dili, often temporarily moving into the refugee camps because of poverty, limited access to food, sanitation, and healthcare services. We enrolled via random sampling children age 6 months to 6 years and excluded those with diarrhoea or fever in the two weeks prior to the study.

Ethics approval was obtained from the Ministry of Health, Timor Leste prior to study commencement and the study 
conformed to the provisions of the Declaration in Helsinki. Parental consent was obtained for all children before enrolment. and their anonymity was preserved. Both the interviewer and mother of the household, completed a household questionnaire in the local language; the form, based on the International Vitamin A Consultative Group and WHO guidelines for assessment of $\mathrm{VAD}$, focused on demographics, maternal educational level, and socioeconomic factors as well as immunization, vitamin $\mathrm{A}$ supplementation, dietary intake, and breast-feeding practices [25].

\section{Anthropometry}

Once the interview was completed, anthropometric datanamely, weight $(\mathrm{kg})$, height/length $(\mathrm{cm})$, and mid upper arm circumference (MUAC, in mm) were gathered. Body weight was measured on children fully clothed in light clothing but without shoes. For infants, a weighing scale was used while infants were lying down. Children older than 2 years old were weighed on a standing scale calibrated before each session. Based on WHO guidelines, weight was measured to the nearest $10 \mathrm{~g}$ and length was measured to the nearest $0.1 \mathrm{~cm}$. Weight for age was measured where the prevalence of malnutrition was assessed by nothing more than actual weight/age in relation to an international standard (e.g., the National Centre for Health Statistics of the United States). Weight for age readings in the 80 to $100 \%$ range were considered normal, 70 to $79 \%$ were considered to indicate moderate malnutrition, and $<70 \%$ were considered to indicate severe malnutrition. For children younger than 2 years of age, their length was measured. For 2 years old and older, height was measured. MUAC was obtained using a measuring tape sectioned in millimetres. MUAC measurements greater than or equal to $135 \mathrm{~mm}$ were considered adequately nourished, whereas measurements less than $135 \mathrm{~mm}$ were considered malnourished.

\section{Ophthalmology examination}

A history of night blindness (XN stage of xerophthalmia) was ascertained from the child's mother using the questionnaire. The following questions were asked: "Can your child see in the daytime? Can your child see at night? Is your child's vision different from other children in the village?" The clinical signs of VAD in the eye were examined by an ophthalmologist using a pen light. The presence of Bitot's spot and corneal lesions was documented. Clinical VAD was defined if xerophthalmia was clinically apparent. Subclinical VAD was deemed to exist if adverse health consequences were present even if in the absence of clinical xerophthalmia.

\section{Statistical analysis}

Data were analysed using the SPSS version 13.0 statistical package. Univariate analysis involved determining the simple frequency distribution of selected variables. Mean, median, and range were calculated for all parameters. The criteria and indicator cut-off values suggested by WHO were used to classify the population's vitamin A status [26]. The results were calculated, tabulated, and analysed to compare the prevalence of VAD indicators as suggested by WHO.

\section{Results}

\section{Demographic data}

We enrolled 89 children from 51 households from two refugee camps around Dili in this study. Most subjects (60.8\%) came from the refugee camp based at the Hospital Nacional Guido Valadares. They originated from 14 different villages, with 19.1\% coming from Bidau and 16.9\% from Becora. The mean age of the children was $36.8 \pm 19.0$ months. The majority of participants (52.8\%) were females; the female children were also older (mean age 40.66 months versus 32.48 months for the male gender). Most of the children were born in health centres, hospitals, or nearby clinics. The mother or grandmother was the primary caretaker. The average number of children per household was 2.27 , with a range of 1 to 5 per household. Most households were small, with 2 to 3 children between 6 and 72 months $(35.3 \%$ of households with 2 children and $27.5 \%$ with 3 children).

\section{Ophthalmic findings of VAD}

No children with definitive clinical ocular signs of VAD were seen. $93.3 \%$ of the children had normal eyes based on the external examination; five children (5.6\%) had purulent conjunctivitis and one child had congenital cataract. The number of children with night blindness in children older than 24 months old, according to the history taken from the mothers, was 5 (5.6\%). Using the WHO cut-off values, a prevalence of night blindness greater than $1 \%$ in children 24 to 72 months of age indicates a public health problem. Of the 5 children with night blindness, 2 were males and 3 females. Both boys had incomplete immunizations due to the mother's "neglect" and low socioeconomic and low educational levels. Comparing the malnutrition status of these children, 4 were in the normal range, while one had moderate malnutrition. All of them consumed foods containing vitamin A fewer than three times a week, but their family had low educational levels.

\section{Vitamin A dietary intake}

Almost all of the children commonly consumed fruit containing vitamin A more than three times a week. Frequently consumed fruits included mangoes (73\%), bananas (43\%), and papayas $(33.7 \%)$. Dark green leafy vegetables (DGLV) were consumed by $60.6 \%$ of the children every day. Animal sources of Vitamin A (e.g., liver, meat, and eggs) were commonly consumed by $65.9 \%$ of the children. Using the WHO cut-off value, this population was not at risk of VAD.

\section{Breast-feeding patterns and weaning practices}

Most children (69.7\%) had been breast fed regularly, while $30.3 \%$ combined it with bottle milk. In addition, 18 children $(20.2$ $\%$ of 89 children) were still being breast fed (mean age of $1.8 \pm$ 0.4 months). Most mothers (28.1\%) stopped breast feeding their children around 3 to 6 months of age. Solid food was introduced to children mostly by 4 months. Comparing these percentages to the WHO cut-off value, the children were at no risk of VAD.

\section{Anthropometry}

According to the recorded weights for age, 63 children (70.8\%) had normal nutrition, 23 (25.8\%) had moderate malnutrition, 
and 3 (3.4\%) had severe malnutrition. MUAC indicated a "normal" nutritional status in $84.3 \%$ of the children while 2 children $(2.2 \%)$ had malnutrition and $13.5 \%$ had moderate malnutrition. Using the WHO cut-off values for the prevalence of low anthropometric values $(<-2 \mathrm{SD})$, the study population is estimated to be a high risk area/population for VAD.

\section{Immunization}

In East Timor, the Department of Health provides every health centre with a special sub-department for immunization even when the child was born elsewhere. The immunization rates in children between 12 to 23 months of age were generally good, as $80.9 \%$ were fully immunized. BCG vaccination coverage was even better, with $98.9 \%$ fully immunized. Only $1.1 \%$ did not get BCG at birth as the firstimmunization because the baby was born at home. Diphtheria-Tetanus-Pertussis (DPT) full immunization rates were $84.3 \%$, whereas $4.5 \%$ did not receive immunizations and $11.2 \%$ had incomplete immunizations. Furthermore, $84.3 \%$ were fully immunized against polio ( $9 \%$ had no polio immunization, $6.7 \%$ had incomplete immunization), and $74.2 \%$ were fully immunized against measles. Using WHO guidelines, the coverage rates for full immunization-particularly for measles-did not fall below $50 \%$ for 12 - to 23 -month-old children, indicating that the sample population was not at risk of VAD.

\section{Vitamin A supplementation}

Vitamin A supplementation was provided to children (usually at 23 months of age) as part of the Department of Health's Initiatives to prevent VAD. In this survey, $80.9 \%$ of the children had received vitamin A supplementation.

\section{Maternal education and literacy}

Most parents knew about sources of vitamin A. According to the survey, only $13.7 \%$ of mothers had no formal education; whereas, most $(86.3 \%)$ had attended formal school from elementary through to tertiary levels. $11.8 \%$ had completed only elementary school and $19.6 \%$ had completed only junior high school, whereas the majority (41.9\%) had completed senior high school. Only $8.9 \%$ had attended tertiary school.

\section{Household income}

In this survey of 51 households, $25.5 \%$ had no regular income, $35.3 \%$ had a small business (e.g., small shops), $7.8 \%$ sold produce (e.g., fruits and vegetables) in the market, and the rest $(31.4 \%)$ had regular incomes working as a teacher or in public employment. Most (62.7\%) earned $\$ 100$ to $\$ 200$ per month, while $33.3 \%$ earned less than $\$ 100$ per month.

\section{Water supply and sanitation}

Most households (70.6\%) had access to safe running water both at home and while at the refugee camp, while $29.4 \%$ had access to well water. Adequate sanitation was provided by international agencies and the local government. When $<50 \%$ of households have a safe water supply, the probability for VAD is high. Using this WHO indicator, the study population was not at risk of VAD.

\section{Access to healthcare}

In this survey, $100 \%$ of the population visited the clinic when they had a health problem. Using this indicator as a cut-off value suggested by the WHO, the population is not at risk of VAD.

\section{Discussions}

VAD is a public health problem, especially in impoverished countries $[2-4,13,27]$. According to WHO, VAD is a clinically significant public health in 39 countries and a subclinical problem in 11 countries [27, 28]. Every year, another 5 to 10 million children develop xerophthalmia; between a quarter and half a million go blind $[7,28]$. To date, no data has been published on the VAD in refugee children in East Timor. Our study found no evidence of clinical VAD; but $5.6 \%$ of the children suffered from night blindness subclinical VAD at a level of mild-moderate public health importance.

Night blindness, a symptom of xerophthalmia, is often present with other ocular VAD signs [29, 30]. Poor adaptation to the dark is the result of a reduced rate of regeneration of rhodopsin in the outer segments of the rods following exposure to light. Assessment of night blindness through interviews, as used in our study, has been validated by several other studies [31-33]. Currently, objective assessment measurements for night blindness such as the portable dark field adaptometer, Vision Restoration Time and pupillary and vision thresholds are being developed, although they have not yet been standardised [34-36]. History of night blindness has been shown to have sensitivity, specificity and positive predictive value of $47.2,98.1$ and $96.2 \%$, respectively, compared with the standard diagnosis procedure using luxometer readings [37]. Due to financial and logistical constraints, we did not measure serum retinol levels or perform conjunctival impression cytology.

In our study, almost $30 \%$ of the children suffered from moderate to severe malnutrition. Families are often fraught with social poverty, including under-education, poor environmental sanitation, and personal hygiene, all of which can contribute toward malnutrition in children with $\operatorname{VAD}[3,4,13,38,39]$. Although vitamin A is an important factor for normal growth, several factors (e.g., micronutrient deficiency, infections, and goitre) may decelerate muscle growth [4, 40]. A child with borderline/marginal vitamin A intake will have very limited vitamin A stores, and dietary problems such as impaired absorption (e.g., gastroenteritis) or a sudden increase in metabolic demand (e.g., growth spurt) may result in the rapid depletion of their already limited reserves $[3,39,41]$. Intestinal worm infections may also directly compete for the intake of vitamin $A$ in addition to appetite suppression $[4,42]$. Infectious diseases decrease children's appetites; infections are especially devastating for the weaned child.

In a previously published study in Timor and Rote Islands, Indonesia, VAD had been associated with severe tuberculosis; MUAC was applied as a measure of tuberculosis severity [43]. Although the reproducibility of MUAC is fair [43], a single measurement of MUAC as in our survey is of less value compared to 
serial measurements in assessing the nutritional status of a child. A single MUAC measurement indicates the cumulative growth, not whether growth is proceeding or not. All anthropometric indices have their limitations since growth is a multi factorial process, and specific nutrient deficiency (e.g., iron, thiamine, zinc) cannot be differentiated. The weight for age index, although easy to measure, has some disadvantages: The precise age of young children is not known in some communities. Healthy children of the same age may have different growth patterns prior to being weighed. Weight is much more labile than height and is, to some extent, a reflection of body composition: Weight gain may occur from tissue fluid increase as well as from increases in muscle or fat. In future studies, somatic measurements should be repeated to estimate the linear growth of this population.

Community healthcare providers and policymakers need to tailor specific comprehensive strategies to improve vitamin A status in at-risk communities, recognising that it is a long-term haul. In order to develop cost-effective VAD programmes, it is helpful to examine possible collaborations with other community health or developmental programmes, such as breast feeding, immunization, primary healthcare, family planning, literacy, and local-level political parties as well as school, church, and other religious and non-governmental organizations. These organizations can be a focal point for promoting vitamin A-rich foods through agricultural gardens and their educational curriculum. Additionally, it is important to ensure that primary and secondary school teachers as well as other community leaders have sufficient knowledge about vitamin $\mathrm{A}$, the consequences of VAD, and knowledge of local foods containing vitamin A. The simplified dietary assessment is a simple and rapid assessment tool to detect population groups at risk for VAD [44, 45] Parental education should encourage family planning to space children, resulting in improved care. Pregnant women should be encouraged to increase their vitamin A intake in their diet [28, 30]. They should not receive large doses of vitamin $A$ as it may be teratogenic, but a daily supplemental dose of 10000 IU over 2 weeks is deemed safe. In addition, mothers should be encouraged to vaccinate children again measles and other diseases as well as increase the rates of exclusive breast feeding to infants younger than 6 months old.

\section{Conclusions}

While there was no clinical VAD, we found that subclinical VAD and malnourishment to be a significant health problem in young East Timorese children living in refugee camps. Activities geared towards health promotion, and changes to local eating habits, lifestyle, and cultural behaviours may ameliorate the health problems of these susceptible children.

\section{Ethical approval}

Ethics approval was obtained from the Ministry of Health, Timor Leste prior to study commencement and the study conforms to the provisions of the Declaration in Helsinki. Parental consent was obtained for all children before enrolment and their anonymity was preserved.

\section{References}

1. Custodio VI, Daneluzzi JC, Custodio RJ, Del Ciampo LA, Ferraz IS, Martinelli CE Jr, et al.Vitamin A deficiency among Brazilian school-aged children in a healthy child service. Eur J Clin Nutr. 2009;63(4):485490 .

2. Kassu A, Andualem B, Van Nhien N, Nakamori M, Nishikawa T, Yamamoto S, et al. Vitamin A deficiency in patients with diarrhea and HIV infection in Ethiopia. Asia Pac J Clin Nutr. 2007;16 Suppl 1:323328.

3. Gorstein J, Shreshtra RK, Pandey S, Adhikari RK, Pradhan A. Current status of vitamin A deficiency and the National Vitamin A Control Program in Nepal: results of the 1998 National Micronutrient Status Survey. Asia Pac J Clin Nutr, 2003;12(1):96-103.

4. Khan NC, Ninh NX, Van Nhien N, Khoi HH, West CE, Hautvast JG. Sub clinical vitamin A deficiency and anemia among Vietnamese children less than five years of age. Asia Pac J Clin Nutr. 2007;16(1):152-7.

5. Gamble MV, Palafox NA, Dancheck B, Ricks MO, Briand K, Semba RD. Relationship of vitamin A deficiency, iron deficiency, and inflammation to anemia among preschool children in the Republic of the Marshall Islands. Eur J Clin Nutr. 2004;58(10):1396-1401.

6. Coles CL, Levy A, Gorodischer R, Dagan R, Deckelbaum RJ, Blaner WS, et al. Subclinical vitamin A deficiency in Israeli-Bedouin toddlers. Eur J Clin Nutr. 2004;58(5):796-802.

7. West KP Jr. Vitamin A deficiency disorders in children and women. Food Nutr Bull. 2003; 24(4 Suppl):S78-90.

8. Bellagio brief: vitamin A deficiency and childhood mortality. Bull Pan Am Health Organ. 1993;27(2):192-7.

9. Milton RC, Reddy V, Naidu AN. Mild vitamin A deficiency and childhood morbidity--an Indian experience. Am J Clin Nutr. 1987;46(5):827-829.

10. West KP Jr. Extent of vitamin A deficiency among preschool children and women of reproductive age. J Nutr. 2002.132(9 Suppl):2857S 2866S.

11. Underwood BA. The role of vitamin A in child growth, development and survival. Adv Exp Med Biol. 1994;352:201-8.

12. Lin J, Song F, Yao P, Yang X, Li N, Sun S, et al. Effect of vitamin A supplementation on immune function of well-nourished children suffering from vitamin A deficiency in China. Eur J Clin Nutr, 2008;62(12):1412-8.

13. Kapil U, Saxena N, Srivastava M, Jailkhani L, Nayyar B, Chikkara P, et al. Assessment of vitamin A deficiency indicators in urban slum communities of National Capital Territory of Delhi. Asia Pac J Clin Nutr. 1996;5(3):170-2

14. McNamee P, Ternent L, Hussein J. Barriers in accessing maternal healthcare: evidence from low-and middle-income countries. Expert Rev Pharmacoecon Outcomes Res. 2009;9(1):41-8. doi: 10.1586/14737167.9.1.41.

15. Semba RD, de Pee S, Sun K, Campbell AA, Bloem MW, Raju VK. Low intake of vitamin A-rich foods among children, aged 12-35 months, in India: association with malnutrition, anemia, and missed child survival interventions. Nutrition. 2010;26(10):958-62. doi: 10.1016/j. nut.2009.08.010

16. Demissie T, Ali A, Mekonnen Y, Haider J, Umeta M. Demographic and health-related risk factors of subclinical vitamin A deficiency in Ethiopia. J Health Popul Nutr. 2009;27(5):666-73.

17. Sitorus RS, Abidin MS, Prihartono J. Causes and temporal trends of childhood blindness in Indonesia: study at schools for the blind in 
Java. Br J Ophthalmol. 2007;91(9):1109-13.

18. Khatib IM, Elmadfa I. High prevalence rates of anemia, vitamin A deficiency and stunting imperil the health status of Bedouin school children in North Badia. Jordan. Ann Nutr Metab. 2009;55(4):358-67. doi: 10.1159/000258632.

19.Sommer A. Vitamin A deficiency and childhood mortality. Lancet, 1992. 340(8817): p. 488-9.

20. Shah SM, Yousafzai M, Lakhani NB, Chotani RA, Nowshad G. Prevalence and correlates of diarrhea. Indian J Pediatr. 2003;70(3):207-11.

21. Woodruff BA, Blanck HM, Slutsker L, Cookson ST, Larson MK, Duffield A, et al. Anaemia, iron status and vitamin A deficiency among adolescent refugees in Kenya and Nepal. Public Health Nutr. 2006;9(1):26-34.

22. Loretti A. Armed conflicts, health and health services in Africa. An epidemiological framework of reference. Med Confl Surviv. 1997;13(3):219-28.

23. Tomkins A. Vitamin and mineral nutrition for the health and development of the children of Europe. Public Health Nutr. 2001;4(1A):91-9.

24. Seal AJ, Creeke PI, Mirghani Z, Abdalla F, McBurney RP, Pratt LS, et al. Iron and vitamin A deficiency in long-term African refugees. J Nutr. 2005;135(4):808-13.

25.25 Years of progress in controlling vitamin A deficiency: looking to the future. Proceedings and abstracts of the XX International Vitamin A Consultative Group Meeting. Hanoi, Vietnam, 12-15 February 2001. J Nutr. 2002;132(9 Suppl):2843S-2990S.

26. Underwood BA, Arthur P. The contribution of vitamin A to public health. FASEB J. 1996;10(9):1040-8.

27. Sommer A. Vitamin A deficiency and the global response. Forum Nutr 2003;56:33-5.

28. Sherwin JC, Reacher MH, Dean WH, Ngondi J. Epidemiology of vitamin A deficiency and xerophthalmia in at-risk populations. Trans R Soc Trop Med Hyg. 2012;106(4):205-14. doi: 10.1016/j.trstmh.2012.01.004.

29. Pal R, Sagar V. Antecedent risk factors of xerophthalmia among Indian rural preschool children. Eye Contact Lens. 2008;34(2):106-8. doi: 10.1097/ICL.0b013e3181379fd7.

30. Akhtar S, Ahmed A, Randhawa MA, Atukorala S, Arlappa N, Ismail T, et al. Prevalence of vitamin A deficiency in South Asia: causes, outcomes, and possible remedies. J Health Popul Nutr. 2013;31(4):413-23.

31. Congdon NG, Dreyfuss ML, Christian P, Navitsky RC, Sanchez AM, Wu LS, et al. Responsiveness of dark-adaptation threshold to vitamin A and beta-carotene supplementation in pregnant and lactating women in Nepal. Am J Clin Nutr. 2000;72(4):1004-9.

32. Husain, L. Using the key informant method to investigate childhood blindness related to vitamin A deficiency disorder in six rural subdistricts in Bangladesh. Community Eye Health. 2007;20(61):7-8.

33. Christian P, Bentley ME, Pradhan R, West KP Jr. An ethnographic study of night blindness "ratauni" among women in the Terai of Nepal. Soc Sci Med. 1998;46(7):879-89.

34. Congdon N, Sommer A, Severns M, Humphrey J, Friedman D, Clement $\mathrm{L}$, et al. Pupillary and visual thresholds in young children as an index of population vitamin A status. Am J Clin Nutr. 1995;61(5):1076-82.

35. Sanchez AM, Congdon NG, Sommer A, Rahmathullah L, Venkataswamy PG, Chandravathi PS, et al., Pupillary threshold as an index of population vitamin A status among children in India. Am J Clin Nutr. 1997;65(1):61-6.

36. Labrique AB, Amanda C. Palmer, Katherine Healy, Sucheta Mehra, Theodor C. Sauer, Keith P. WestJr, et al. A novel device for assessing dark adaptation in field settings. BMC Ophthalmol. 2015;15:74. doi: 10.1186/s12886-015-0062-7.

37. Ngah NF., et al. Ocular manifestation of vitamin A deficiency among Orang asli (Aborigine) children in Malaysia. Asia Pac J Clin Nutr. 2002.11(2):88-91.

38. Ahmed F, A Azim, Akhtaruzzaman M. Vitamin A deficiency in poor, urban, lactating women in Bangladesh: factors influencing vitamin A status. Public Health Nutr. 2003;6(5):447-52.

39. Gamble MV, Palafox NA, Dancheck B, Ricks MO, Briand K, Semba RD. Carotenoid status among preschool children with vitamin A deficiency in the Republic of the Marshall Islands. Asia Pac J Clin Nutr. 2004;13(4):336-40.

40. Katz J, Khatry SK, West KP, Humphrey JH, Leclerq SC, Kimbrough E, et al, Night blindness is prevalent during pregnancy and lactation in rural Nepal. J Nutr. 1995;125(8):2122-7.

41. Donnen P, Brasseur D, Dramaix M, Vertongen F, Ngoy B, Zihindula $\mathrm{M}$, et al. Vitamin A deficiency and protein-energy malnutrition in a sample of pre-school age children in the Kivu Province in Zaire. Eur J Clin Nut. 1996;50(7):456-61.

42. Kisinza WN, Kisoka WJ, Mutalemwa PP, Njau J, Tenu F, Nkya T, et al. Community directed interventions for malaria, tuberculosis and vitamin A in onchocerciasis endemic districts of Tanzania. Tanzan J Health Res. 2008;10(4):232-9.

43. Pakasi TA, Karyadi E, Wibowo Y, Simanjuntak Y, Suratih NM, Salean $\mathrm{M}$, et al. Vitamin A deficiency and other factors associated with severe tuberculosis in Timor and Rote Islands, East Nusa Tenggara Province, Indonesia. Eur J Clin Nutr. 2009;63(9):1130-5. doi: 10.1038/ ejcn.2009.25.

44. Pedro RA, Candelaria LV, Bacos FF, Ungson BD, Lanot EM. A simplified dietary assessment to identify groups at-risk for dietary vitamin A deficiency. Asia Pac J Clin Nutr. 1996;5(3):164-9.

45. Tienboon P, Wangpakapattanawong P. Vitamin A status of the minority ethnic group of Karen hill tribe children aged 1-6 years in Northern Thailand. Asia Pac J Clin Nutr. 2007;16(1):158-62. 